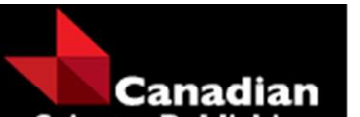

Science Publishing

Canadian Journal of Forest Research Revue canadienne de recherche forestière

\title{
A Replanning Approach for Maximizing Woodland Caribou Habitat alongside Timber Production
}

\begin{tabular}{|r|l|}
\hline Journal: & Canadian Journal of Forest Research \\
\hline Manuscript ID & cjfr-2016-0254.R2 \\
\hline Date Submitted by the Author: & 24-Feb-2017 \\
\hline Complete List of Authors: & $\begin{array}{l}\text { Martin, Andrew; University of Toronto, Faculty of Forestry } \\
\text { Ruppert, Jonathan; University of Toronto, } \\
\text { Gunn, Eldon; Dalhousie University } \\
\text { Martell, David; University of Toronto, }\end{array}$ \\
\hline Keyword: & $\begin{array}{l}\text { linear programming, economic values, ecological values, graph theory, } \\
\text { forest management }\end{array}$ \\
\hline $\begin{array}{r}\text { Please Select from this Special } \\
\text { Issues list if applicable: }\end{array}$ & N/A \\
\hline \multicolumn{2}{|l}{} \\
\hline $\begin{array}{l}\text { Note: The following files were submitted by the author for peer review, but cannot be converted to } \\
\text { PDF. You must view these files (e.g. movies) online. }\end{array}$ \\
\hline Images.zip \\
\hline
\end{tabular}

\section{SCHOLARONE}

Manuscripts 
1 Title: A Replanning Approach for Maximizing Woodland Caribou Habitat alongside Timber

2 Production.

4 Andrew B. Martin ${ }^{1 *}$, Jonathan L.W. Ruppert ${ }^{1}$, Eldon A. Gunn ${ }^{2 \dagger}$, David L. Martell ${ }^{1}$ 5

$6{ }^{1}$ Faculty of Forestry, University of Toronto, 33 Willcocks Street, Toronto ON, Canada, M5S

$7 \quad{ }^{2}$ Department of Industrial Engineering, Dalhousie University, Halifax NS, Canada

$8 \overbrace{}^{\dagger}$ Deceased

$9 \quad *$ corresponding author:

Andrew B. Martin

Eco Modelling Ltd.

73 Bathurst St. Suite 403

Toronto, ON, M5V 2P6

Telephone: 1-647-861-9100

Email: andrew@ecomodelling.co

16

17 Type of Article: Standard Article

18

19 Manuscript Date: March 15, 2017

20

21 Keywords (3-5): Linear programming, economic values, ecological values, graph theory 


\section{Abstract}

25 We present a forest harvest scheduling model that meets timber harvest targets while maximizing

26 a proxy measure of woodland caribou habitat based upon the configuration of preferred habitat

27 on the landscape. Woodland caribou within the boreal forest region in Canada tend to prefer

28 mature jack pine forest stands which tend to be rich in their preferred resource, lichen, and also

29 reduce predation pressure. This can create conflict with industrial wood supply needs. We

30 designed a model that can be used to identify good harvest scheduling plans given these

31 competing objectives. Our approach is to use a series of sequential linear programming models

32 that are solved within a replanning framework. Specifically, each individual linear programming

33 model seeks to produce a solution that will meet timber harvest targets while minimizing the

34 harvest of high quality woodland caribou habitat stands. Stands are assessed with respect to their

35 suitability as woodland caribou habitat based on their contribution to the overall landscape

36 Equivalent Connected Area (ECA), a combined spatial measure of preferred habitat amount and

37 its connectivity. We used our model for a case study of the Trout Lake forest in northwestern

38 Ontario, Canada, and found that our model creates approximately $10 \%$ more caribou habitat than

39 an earlier heuristic procedure and 30\% more caribou habitat than the prevailing woodland

40 caribou habitat forest management plan in the Trout Lake forest while meeting the same timber

41 harvest targets. 


\section{Introduction}

Woodland Caribou conservation is an important forest management objective throughout Canada, including the province of Ontario. That importance is due largely to the fact that Woodland Caribou (Rangifer tarandus caribou), hereafter referred to as caribou, are listed as being threatened under the Species at Risk Act (SARA) (COSEWIC, 2000) because of recent range recession that has been observed within regions where industrial activities occur (Bergerud 1974; Environment Canada 2011). In response to this listing, the Ontario Ministry of Natural Resources and Forestry (OMNRF) has developed a spatial harvest scheduling plan, the Dynamic Caribou Habitat Schedule, which is often referred to as the caribou mosaic. One of the caribou mosaic's objectives is to ensure that a specified amount of caribou habitat is maintained at all times across Ontario (OMNR 2014). Specifically, the caribou mosaic harvesting strategy was developed in response to the negative impacts of anthropogenic activities such as roads and harvesting, which have contributed to caribou range recession in Ontario (Bergerud 1974; Vors et al. 2007; McGreer et al. 2015). Its design reflects the need to address caribou habitat needs when developing strategic timber harvest plans and road building plans (OMNR 2014) as both timber harvesting and road building activities reduce the amount of preferred caribou habitat in a forest and increase the fragmentation of preferred habitat, making foraging and calving less successful due to the accompanying changes in the configuration and reduction in the amount of preferred resources (O’Brien et al. 2006; Thompson et al., 2014). Moreover, Wittmer et al. (2005) and others have noted that anthropogenic activity facilitates the movement of boreal species of animals and alters the forest landscape to increase the amount of early seral forest that can potentially lead to increased predation pressure on caribou. This results from increases in early seral forest that promote increases in the abundance of white-tailed deer (Odocoileus 
70 virginianus) and moose (Alces alces andersoni), which lead to subsequent increases in the

71 abundances of predators such as black bears (Ursus americanus) and wolves (Canis lycaon) that

72 will opportunistically prey on caribou.

73 Earlier research (Ruppert et al., 2016) found that the caribou mosaic is not optimal for

74 joint planning of timber harvesting and caribou habitat conservation. The heuristic developed by

75 Ruppert et al. (2016) (henceforth referred to as the harvesting heuristic) outperformed the

76 caribou mosaic plan by maintaining $79 \%$ of the maximum possible amount of caribou habitat

77 versus the caribou mosaic which maintained $60 \%$ of the maximum possible amount of caribou

78 habitat. The maximum possible amount of caribou habitat is defined as the amount of caribou

79 habitat measured using a no-harvest model over the same planning horizon and forest. To

80 achieve that outcome, Ruppert et al. (2016) used a graph theory approach, where preferred

81 habitat patches of caribou are nodes and potential movement paths for caribou are arcs

82 connecting those nodes. Specifically, they measured caribou habitat using the Equivalent

83 Connected Area (ECA) metric which is based upon the amount of preferred habitat patches and

84 how well they are connected on the landscape (Saura et al., 2011). The ECA, which is based

85 upon the spatial configuration of preferred stands, is computed by first classifying forest stands

86 with respect to the quality of caribou habitat they provide. The classification scheme we used

87 (which is described in Table 1) rates stands from 1 to 9 with 1 being the most preferred habitat

88 (mature jack pine stands, rocky outcrops and shallow soil sites) and 9 being the least preferred

89 habitat (stands near recently harvested areas, roads and utility corridors). Using this

90 classification, potential movement paths are created using a cost surface (planning units assigned

91 values in Table 1), whereby the potential movement of caribou or arcs are constructed to

92 represent the least costly path between nodes (i.e., least-cost paths are a function of the distance 
93 and additive costs of each arc along a cost surface) (Adriaensen et al. 2003; Fall et al. 2007). The

94 ECA value for each forest stand is then computed based on the marginal contributions of

95 individual patches of caribou habitat, determined from the simulation, to the overall habitat

96 connectivity of the landscape (Ruppert et al., 2016). Finally, a heuristic harvest value of each

97 stand is calculated, which is a weighted function of the volume of merchantable wood in the

98 stand were it to be harvested and the decrease in suitable habitat that might result were that to

99 happen. This methodology allows one to attribute both the caribou habitat value and its potential

100 timber harvest value (in terms of that caribou value and the amount of merchantable timber) to

101 each forest stand, which can be subsequently used in heuristic and optimization approaches.

102 We utilize this caribou value for forest stands and advance the research of Ruppert et al.

103 (2016) by developing an optimization framework that allows one to identify timber harvest

104 schedules that provide a higher ECA value for the landscape than their harvesting heuristic while

105 meeting the same timber harvest targets. We accomplish this by replacing the harvesting

106 heuristic with a linear programming (LP) optimization model (Dantzig, 1963), and running that

107 model repeatedly within a replanning framework. However, the non-linear spatial nature of the

108 ECA metric makes it difficult to incorporate it directly in LP models. To deal with this non-

109 linearity we incorporate the ECA calculations in a replanning framework. Replanning has been

110 used in forest management planning in the past, particularly for dealing, for example, with

111 uncertainty related to supply chain planning (Epstein et al., 1999), and fire losses (Savage et al.,

112 2010). Specifically, in the replanning framework, LP models are run sequentially, each starting

113 with its first period beginning at the start of the next period of the planning horizon, so the first

114 LP model has its first period as period 1 of the planning horizon, the second LP has its first

115 period as period 2 of the planning horizon, the third LP has its first period as period 3 of the 
116 planning horizon, etc. After each LP model is solved, new ECA values are computed based on

117 the assumption that the first period harvests from the most recent LP model take place, and used

118 to update the LP for the next period.

119 Forest management planners have used strategic planning LP models to help balance

120 trade-offs between competing economic and environmental objectives for over 50 years (Gunn,

121 2007). Some of those that specifically addressed wildlife management include Bettinger et al.

122 (1997) who used Tabu Search to create contiguous blocks of habitat for Rocky Mountain Elk

123 (cervus elephas nelson). Bevers \& Hof (1999) used an LP model to model population dynamics

124 to conserve habitat for species that have minimum inter habitat patch distance requirements

125 alongside timber harvesting. Another approach used by Gustafson et al. (2006) had two stages of

126 linear programming and a simulation model to first optimize timber harvesting and then assess

127 the quality of wildlife habitat that the optimized harvesting schedule produced. Öhman et al.

128 (2011) used stand neighborhoods in a mixed integer programming model to maximize hazel

129 grouse (tetrastes bonasia) habitat alongside timber harvesting in Northern Sweden. With respect

130 to woodland caribou, Schneider et al. (2012) applied optimization methods to determine

131 woodland caribou habitat reserves in Alberta, considering cost, industrial footprint, deer

132 presence, and climate change. However, timber harvesting was not central to their work. More

133 recently, Cui and Moore (2016) described a study in which the Ontario Ministry of Natural

134 Resources and Forestry used the spatially explicit Patchworks goal programming modelling

135 framework developed by Spatial Planning Systems ${ }^{1}$ in conjunction with their own Zone

136 Delineation Tool to evaluate trade-offs involving goals associated with caribou habitat, road

137 construction and other values when delineating and specifying the timing of harvests to mosaic

138 blocks for the caribou mosaic.

\footnotetext{
${ }^{1}$ http://www.spatial.ca
} 
Öhman et al.’s (2011) model is an example of a spatially explicit integer programming

140 (IP) model. In spatially explicit IP models stands are represented by integer variables, and the

141 spatial conditions being optimized are represented in the IP model as variables and constraints.

142 This differs from our approach where continuous variables represent stands and the spatial

143 conditions being optimized are represented by a proxy in our LP models. A spatially explicit IP

144 model that integrated forest harvesting and ECA computations that could be solved to optimality

145 would likely find better solutions than our approach; however, such a model would not be

146 computationally tractable using today's technology. We find our approach to be necessary

147 because the size of the forest we modelled is two orders of magnitude larger than those typically

148 represented in spatial IP models, and spatial IP models become increasingly difficult to solve as

149 problem size increases. For exmple, Öhman et al (2011) use 904 stands while our model uses

150164,851 stands. More recently St. John et al. (2016) used an Optimal Corridor Construction

151 Approach to create corridors of appropriate width and length while scheduling timber harvests

152 with a spatially explicit IP model to develop habitat corridors for reindeer that were herded

153 between two areas alongside timber harvests in a forest with 1996 stands.

155 Methods

156 Study area and harvesting strategies

157 Our analysis was carried out for the Trout Lake Forest Management Unit in Northwestern

158 Ontario, Canada (Figure 1). We used Forest Resource Inventory (FRI) data from OMNRF, which

159 was last updated in 2012. The FRI is an inventory of forest, ecological, and land use conditions

160 that describes 555,000 square kilometers of Ontario's forest and wetlands (OMNR, 2009b). The

161 Trout Lake Forest is an area of approximately 1 million hectares, where there are 164,851 square 
162 forest stands at a size of 6.25 ha each that were created by Ruppert et al. (2016), so that a cost

163 surface could be developed for our graph theory approach. Each stand is then classified as being

164 one of 12 forest cover types that fall under 4 different silviculture regimes following current

165 management plans for the Trout Lake Forest. More than $80 \%$ of the forest canopy is composed

166 of both black spruce (Picae mariana) and jack pine (Pinus banksiana).

167 We build upon some of the previous contributions to forest planning that address wildlife 168 management by incorporating a graph theory framework into an LP model through the use of

169 replanning methods. While the harvesting heuristic produces better ECA solutions than the

170 current plan (caribou mosaic), the LP model embedded within a replanning framework bases

171 harvesting decisions on more information than is available to the harvesting heuristic. The

172 harvesting heuristic uses a myopic approach to specify which stands to harvest each period, one

173 period at a time. For example, when it prescribes decisions to be implemented in period 1, it does

174 not consider the impact of those decisions on harvesting decisions in period 2 or any other future

175 period. By embedding an LP model in a replanning framework we can to some extent overcome

176 this limitation, because it will incorporate consecutive harvests into harvesting decisions for each

177 period.

179 Harvest scheduling LP model

180 To model the relationship between caribou habitat and timber production in the Trout

181 Lake forest, we developed a Model I form of timber harvest scheduling LP model (Johnson \&

182 Scheurman, 1977) that identifies which stands to harvest in each period to meet the periodic

183 harvest targets while maximizing a specified objective function. A Model I framework was used 
184 because Model I maintains each stand's spatial identity which is needed to measure the forest's

185 ECA. The structure of our LP model is as follows:

186

$187 \quad$ Sets

$188 T$ : Periods

189

$190 \quad I:$ Stands

191

$192 J[i]:$ Prescriptions that can be applied to stand $i \in I$

193

$194 H[t]$ : Stand and prescription combinations, $(i, j): i \in I, j \in J[i]$, that are eligible for harvest

195 during period $t \in T$

196

$197 Z$ : Stand and prescription combinations, $(i \in I, j \in J[i]) \in H[1]$, that schedule the stand for

198 harvest in period 1 where the stand will transition to a higher caribou habitat classification in

199 period 2 if it is not harvested in period 1.

$201 \quad$ Parameters

$202 V[i, j, t]:$ Volume of wood available for harvest from stand $i \in I$, managed under prescription $203 j \in J$, in period $t \in T$

204

$205 E c a[i, j, t]:$ Measure of the ECA of stand $i \in I$, managed under prescription $j \in J[i]$, in period $206 t \in T$. 
208 Dist $[i]$ : Distance in meters of stand $i \in I$, from the nearest caribou habitat patch

209

210 Target $[t]:$ The harvest volume target for period $t \in T$

211

212 Area[i]: Area of stand $i \in I$

213

$214 H \operatorname{Hal}[i, j, t]:$ Heuristic harvest value of stand $i \in I$, managed under prescription $j \in J[i]$, in

215 period $t \in T$

216

217 Variables

$218 x[i, j]:$ Area of stand $i \in I$ managed under prescription $j \in J[i]$

219

$220 \mathrm{z}$ : Total area of the stands harvested in period 1 that would transition to a higher caribou habitat

221 classification if they were not harvested during period 1. This variable only applies to period 1 of

222 each LP model.

223

224 The variable set $x[i, j]$ represents the area of stand $i$ to be managed under silvicultural 225 prescription $j$, where a silvicultural prescription describes the management of a stand (e.g., the 226 timing and type of harvesting, regeneration, and silvilcultural treatments) over the entire

227 planning horizon. All of our model prescriptions were generated using the prescription generator 228 described in Martin et al. (2016), and are either clearcut or "do nothing" prescriptions. 
230 Objective

$\operatorname{Max} \sum_{\substack{t \in T \\(i, j) \in H[t]}} \operatorname{Hval}[i, j, t] * x[i, j]-\sum_{(i, j) \in Z} x[i, j]$

The objective function (equation 0 ) is structured to maximize the harvest value of the

232 harvested stands subject to a penalty for harvesting stands that will transition to a better caribou

233 habitat classification category in the next period if they are not harvested. For example, if a Jack

234 Pine stand is 57 years old in period 1 then it has a caribou habitat classification 4 . If that stand is

235 not harvested in period 1 it will be 64 years old in period 2, so it will have a caribou habitat

236 classification 1 at that time, see Table 1 . We penalize the harvesting of such stands in period 1 to

237 discourage harvesting them by assigning a coefficient of -1 to the $x[i, j]$ variables where $(i, j)$

238 belongs to $\mathrm{Z}$ in the objective function.

240 Constraints

$\sum_{\substack{i \in I \\ j \in J[i]}} V[i, j, t] * x[i, j]=\operatorname{Target}[t] \quad t \in T$

$$
\sum_{j \in J[i]} x[i, j]=\operatorname{Area}[i] \quad i \in I
$$

Equation 1 states that the volume harvested in each period must equal the harvest targets

244 that the caribou mosaic must achieve for that period. Equation 2 describes the Generalized

245 Upper Bound (GUB) constraints (Dantzig and Van Slyke, 1967), which state that no more than

246 the total area of a given stand can be assigned to prescriptions. 


$$
\operatorname{Hval}[i, j, t]=v[i, j, t]-\left(\frac{e c a[i, j, t]}{1+\operatorname{dist}[i]}\right) \quad i \in I, j \in J[i], t \in T
$$

250 difference between the volume in a stand, and the stand's contribution to forest's ECA divided

251 by that stand's distance from the nearest habitat patch (Ruppert et al., 2016).

We assume that following a harvest, stands regenerate with the same growth and yield

253 attributes that they had prior to harvest. Stand mortality and stochastic disturbances (e.g., fire,

254 insect, and storm damage) are not considered because the focus of this paper is a comparison of

255 our optimization model with the harvesting heuristic which does not consider these events.

256 Additionally, the development of spatial stochastic models would require a large undertaking in

257 terms of development that is beyond the scope of this paper.

The ECA is a spatial attribute of a forest stand because it is based upon the connectivity

259 of patches of caribou habitat in each period. For example, the contribution of each stand to the

260 ECA of the forest depends on the attributes of that stand as well as the attributes of all the other

261 stands on the landscape. At the same time, the contributions to ECA of all the stands around it in

262 part depend on the attributes of that stand. This non linearity makes it impossible to use an LP

263 model to optimize the ECA of the forest explicitly and that is why we optimize a proxy measure

264 for a stand's contribution to ECA, its heuristic harvest value (Equation 4). We then integrate the

265 heuristic harvest value into a replanning framework to compute the ECA of the forest at the end

266 of every period. Figure 2 illustrates this framework.

The premise of the framework is as follows. We compute the ECA at the start of the

268 planning horizon based on the initial state of the forest. We then incorporate the ECA values in

269 our LP model for an 11 period planning horizon that begins in period 1, and solve it. The 
270 solution to the LP model prescribes harvesting and silvilculture actions for the entire planning

271 horizon. We then use this solution to determine the predicted structure of the forest after period 1

272 growth and harvesting have taken place to compute the ECA of the forest at the end of period 1.

273 Then, we use this ECA to generate the LP model for a 10 period planning horizon beginning in

274 period 2, and solve it. Using the first period solution of this LP (corresponding to the second

275 period of the model) we compute the ECA at the end of the second period, and use it to generate

276 the LP for a 9 period planning horizon beginning in period 3. We repeat this process for the

277 entire 11 period planning horizon. We construct our final solution from the first period of each of

278 the 11 solutions. In practice, only the first period of the model solution would be implemented.

279 All of our models were generated using AMPL (Fourer et al. 1993), the mathematical

280 programming modelling language, and solved using the Gurobi 6.0 (Gurobi, 2015) optimization

281 solver in the order of 2 minutes using a Windows 7 workstation with an i5-3570 $3.4 \mathrm{GHz}$

282 processor and 16GB of RAM. ECA computations were carried out using ArcGIS's arcpy library,

283 and ECA computations that were carried out at the end of each period took on the order of 30

284 minutes.

285

286

Harvesting strategy comparisons

287 We compare the replanning framework model solutions to the solutions generated by the

288 harvesting heuristic to demonstrate that by considering the entire planning horizon, the

289 replanning framework can improve upon the ECA that the harvesting heuristic achieved. We

290 include ECA caribou habitat measures from the caribou mosaic and a no harvesting model for

291 reference. We then use the replanning framework to assess the impact on the ECA metric, of 
292 varying harvest levels, by running models that have harvest targets of $80 \%, 50 \%$, and $20 \%$ of the 293 current planned harvest targets.

294 The caribou mosaic harvesting strategy uses a spatial zoning approach to allocate

295 harvesting in a deterministic manner over the course of the planning horizon (OMNR, 2009a).

296 Specifically, stands have been divided into eight spatially non-contiguous blocks, where each

297 stand belongs to one and only one block, which determines the period during which the stand can

298 be harvested. Some blocks are no-harvest zones (reserves), some are harvest-anytime zones and

299 others can only be harvested once during specific 20-year windows once over the course of a

300 100-year planning horizon. Following Ruppert et al., (2016) we do not include constraints on the

301 timing of the harvesting of those blocks in our analysis and we do not schedule any harvesting in

302 the no-harvest blocks. Also, based on the caribou mosaic harvest plan, periodic harvest volumes

303 were established a priori using the Strategic Forest Management Model (SFMM) forest planning

304 tool (OMNR, 2007), an aspatial strategic linear programming model, and the planning horizon of

305 our model is set to 11 time periods. Each period is 10 years long except the first which is only 7

306 years long, because in 2012 we were currently 3 years into that period. Further details of the

307 harvesting heuristic can be found in Ruppert et al. (2016). To summarize, the heuristic calculates

308 a heuristic harvest value for each stand at the beginning of each planning period and schedules

309 the harvesting of stands in order of decreasing harvest value until harvest volume targets are met

310 for that period. After such harvesting, all stands develop according to yield curves defined for the

311 Trout Lake Forest (Penner et al. 2008), which are similar to rates of deterministic succession in

312 models used for strategic forest planning in Northwestern Ontario (OMNR 2009a).

\section{Results}


We compared the results obtained using our replanning framework LP model with the

315 results obtained using the harvesting heuristic, the caribou mosaic, and a no harvesting solution.

316 All models - with the exception of the no harvesting model - had the same timber harvest

317 volume targets. The harvesting heuristic and the replanning framework required similar amounts

318 of time to run, around 3-4 hours for the entire planning horizon, with almost all of that time

319 dedicated to computing the ECA. We found that the replanning framework achieves $85 \%$ of the

320 maximum possible forest ECA achievable over the planning horizon. The maximum possible

321 forest ECA achievable over the planning horizon is the sum of each period's ECA obtained by

322 running the no harvest model. The replanning framework's result compares favorably with the

323 harvesting heuristic which achieves $79 \%$ of that maximum and the caribou mosaic, which

324 achieves only $60 \%$ of it. The harvesting heuristic and the caribou mosaic plan were compared in

325 Ruppert et al. (2016), so here we focus our comparison of the replanning framework with the

326 harvesting heuristic.

327 Analyzing the spatial arrangement of harvests, we found that in the replanning

328 framework and the harvesting heuristic solutions harvests have similar spatial arrangements.

329 However, we note from our visual inspection of Figure 4, that the replanning framework selects

330 harvests that are more tightly spatially clustered than the harvesting heuristic. This is shown by

331 the darker, less dispersed, harvest map that results from the use of the replanning framework.

332 Examination of the patches of caribou habitat created at the end of the last period of the

333 planning horizon reveals that both models produce similar large patches of caribou habitat

334 (Figure 5) although the replanning framework creates more high quality patches (corresponding

335 to the lightest grey in the diagram) habitat, shown more clearly in the sections from the northeast

336 corner and western edge of the forest: panels $\mathrm{C} / \mathrm{D}$ and $\mathrm{E} / \mathrm{F}$ (Figure 5). 
Having found that the replanning framework can create more caribou habitat than the

338 harvesting heuristic, our next step was to assess the impact that reducing harvest volume targets

339 might have on caribou habitat. Using the replanning framework for all scenarios, we found that

340 by reducing harvest volumes after the first period by $20 \%, 50 \%$, and $80 \%$ we were able to

341 achieve $89 \%, 94 \%$, and 96\%, respectively, of the maximum caribou habitat (Figure 6).

342 .

\section{Discussion}

344 Overall there is benefit to using the replanning framework to prescribe harvesting

345 decisions over the entire planning horizon. The replanning framework achieves more of the

346 maximum achievable preferred caribou habitat than either the harvesting heuristic or the caribou

347 mosaic. Further, much of this increase, particularly in comparison with the harvesting heuristic,

348 is observed during the early and middle periods of the planning horizon during which there is

349 less uncertainty concerning natural disturbance processes than later in the planning horizon. This

350 increase is attributable to the replanning framework prescribing decisions over the entire

351 planning horizon compared with the myopic harvesting heuristic, which prescribes them period

352 by period. Both the harvesting heuristic and the replanning framework use the same criterion to

353 select stands for harvest. It's therefore not surprising that the harvest maps generated by the two

354 models look similar (Figure 4). The primary difference between them is that the harvests are

355 more spatially clustered on the replanning framework map than on the harvesting heuristic map

356 (Figure 4). The replanning framework therefore generates solutions that can be characterized by

357 an overall reduction in the amount of habitat lost and less fragmentation of preferred caribou

358 habitat. This results from the replanning framework having a smaller set of stands that it can 
359 harvest without penalty than the harvesting heuristic, so it consistently selects the same stands 360 for harvest.

The final period caribou habitat maps generated by the replanning framework and the

362 harvesting heuristic also look similar (Figure 5), but we can see that the results of the differences

363 in harvesting decisions between the models in these maps. The replanning framework has more

364 light grey area (most preferred caribou habitat) than the harvesting heuristic, particularly in the

365 northeast corner of the forest (Figure 5), the top-center, and along the western edge (Figure 5),

366 reflecting areas where harvesting has not taken place for at least 6 or 7 periods. This increase in

367 the area of high quality caribou habitat is the result of having more clustered harvests when the

368 replanning framework is used. Not surprisingly, Figure 6 reveals that decreased harvest levels

369 increase the ECA. Further, the increase in the ECA is proportional to the decrease in harvest

370 volume and is roughly consistent from period to period. This means that if necessary, it is

371 possible to increase the amount of caribou habitat on the landscape by decreasing harvest levels,

372 though we find that substantial gains in caribou habitat require substantial reductions in harvest

373 levels.

374 We used a decreasing length planning horizon in our replanning framework rather than a

375 rolling planning horizon. We did so because we wanted to compare the replanning framework

376 and the harvesting heuristic for the same problem and planning horizon. Using a rolling planning

377 horizon with our replanning framework produces solutions that have lower ECA than the

378 decreasing length planning horizon model. In our replanning framework we do not use terminal

379 forest condition constraints, so nothing ensures that there is adequate timber available to harvest

380 in periods after 11 to meet future harvest targets. That is, when our replanning framework is

381 used, the terminal state of the forest has high ECA, but may not be in a condition such that future 
382 harvest targets can be met, or may only be met at great cost to caribou habitat. With a rolling

383 planning horizon model there are harvest targets for 22 periods. In order to meet harvest targets

384 in periods after 11 it may be necessary to cut more high value caribou habitat before period 11,

385 leading to solutions that produce less ECA in the first 11 periods than the decreasing planning

386 horizon model. The policy and forest management planning implications of this is that there is a

387 need to look further ahead than 100 years to accurately plan for sustainable caribou habitat.

388 One implication of using LP is that stands may receive partial harvest assignments (i.e.,

389 the model may schedule a particular stand to have some fraction of its area harvested according

390 to one schedule, and the rest following one or more other schedules). In our model that optimizes

391 a spatial attribute of the forest, the ECA, stands that are split between multiple harvest schedules

392 could pose a problem to accurately computing individual stands' contributions to ECA.

393 Fortunately, use of an LP model had minimal impact with respect to fractional stand harvests for

394 two reasons.

395 The first is that we use a Model I (Johnson \& Scheurman, 1977) LP formulation. In forest

396 management models of large forests the majority of variables in a Model I LP model have what

397 are known as Generalized Upper Bound (GUB) constraints (Dantzig \& Van Slyke, 1967).

398 Specifically, the variables that represent stands have GUB constraints. Dantzig and Van Slyke

399 (1967) observed that LP models with GUB constraints have the characteristic that in an optimal

400 solution the number of variables having a GUB constraint that can receive a partial assignment

401 (i.e., the number of stands that can receive more than one harvest schedule) has an upper bound

402 of the number equal to the number of non-trivial, non-GUB, constraints in the model. In our case

403 this means that no more than 11 of 164,851 stands were split between more than one harvest

404 schedule. 
Second, we compute ECA by treating stands that are partially harvested as if the entire

406 stand is harvested. This means that we don't overestimate the amount of caribou habitat in the

407 forest at the cost of potentially slightly underestimating the amount of caribou habitat.

408 In each LP model in our replanning framework the number of harvest target constraints

409 determined the number of stands that did receive partial harvest assignments. This begs the

410 question, how would our replanning framework perform on more complicated models? The

411 answer will depend on how complicated the models are. Our method of treating partially

412 harvested stands as if they were completely harvested to compute caribou habitat will likely

413 prevent modelers from overestimating the amount of caribou habitat when using the replanning

414 framework. The potential underestimation of caribou habitat due to this method will depend on

415 how complicated the LP models are.

For forests that are smaller than ours an option is to revisit IP models, and the possibility

417 of representing caribou habitat via ECA in an integrated spatial model. We encourage

418 researchers to investigate modelling ECA using IP. ECA could still be challenging to compute

419 exactly within an IP model because it must take into account relationships from each stand to the

420 rest of the stands in the forest. However, a smaller forest would make these computations

421 substantially easier to perform than they are for the Trout Lake forest. It may also be fruitful to

422 employ an approximation similar to the stand neighbourhoods of Öhman et al. (2011).

423 Several other extensions of this work are possible as well. Incorporating stand mortality,

424 stochastic disturbances, road network construction and harvest costs into the replanning

425 framework could make the model more realistic. Further, if this model were to be implemented

426 in practice, it would be helpful to run it with a full rolling planning horizon instead of a

427 decreasing planning horizon to produce more long term sustainability measures. It would also be 
428 useful to investigate the inclusion of habitat patch connectivity constraints such as those in

429 Carvajal et al. (2013) to the LP models so that a better approximation of the impact on forest

430 ECA of harvesting a stand could be incorporated into the model. Forcing temporal connectivity

431 between patches such as in Toth \& McDill (2007) could be another valuable extension of our

432 work that should be considered.

433 Our framework is flexible in that harvesting decisions are prescribed by incorporating

434 replanning directly into the strategic forest management model, where harvesting decisions take

435 into account changing forest values and consider future potential caribou habitat. This approach

436 has been found to be more flexible than traditional optimization approaches and can more

437 accurately capture changes in values that may occur through time, across the forest landscape

438 (e.g., fire), marketplace (e.g., forest products) and ecological values (e.g., caribou habitat) (Gunn,

439 1991; Epstein et al. 1999; Savage et al., 2010). Additionally, the framework we present could be

440 extended to include additional economic and ecological values. For example, other boreal

441 species are considered important to boreal forest economies, such as the American Martin

442 (Martes Aericana) for trapping (OMNR, 2014). Including multiple values would require an

443 adjustment to the harvest heuristic value calculation, which is beyond the scope of this study, but

444 could make the replanning framework approach more all-encompassing by incorporating

445 multiple economic and ecological values. 
We have developed and used a replanning linear programming framework for

450 maximizing caribou habitat alongside timber production. Our replanning framework is based on

451 the use of a series of linear programming models that are run in sequence, where the results of

452 each model are used to compute the ECA of the forest, which is then incorporated in the

453 subsequent linear programming model. The replanning framework is an improvement over the

454 harvesting heuristic presented in Ruppert et al. (2016) because it considers what can happen over

455 the entire planning horizon, whereas the Ruppert et al. (2016) harvesting heuristic only

456 prescribes decisions on a period by period basis. This allows the replanning framework to avoid

457 harvesting stands that will soon become valuable caribou habitat if left undisturbed.

When we used the replanning framework we achieved approximately $10 \%$ more ECA in

459 the forest than the harvesting heuristic, and approximately $30 \%$ more ECA than the caribou

460 mosaic. We also showed that the increase in caribou habitat we could expect to achieve by

461 decreasing harvest targets. Using the replanning framework, when decreasing harvests by $20 \%$,

462 we're able to increase the ECA by $4 \%$, and when decreasing harvests by $80 \%$ we're able to

463 increase ECA by $11 \%$. Our results indicate that the largest improvements may be achieved

464 through the spatially explicit selection of stands for harvest (by using the replanning framework)

465 and not necessarily by altering the overall amount of harvest on the landscape.

In this study, we present a replanning framework model that improves habitat

467 configuration (a function of habitat area and connectivity) for caribou the most, compared with

468 other harvesting strategies, in our case study area in northwestern Ontario. However, as this

469 planning strategy focuses on improving the configuration of old-growth forest stands, this model

470 could also be extended to other systems where similar improvements in old growth stands are

471 desired to achieve management goals. In summary, we find that our strategic planning approach 
472 (replanning framework) can be a useful tool to help guide managers when faced with the

473 conservation and restoration of old-growth forest stands alongside industrial timber production.

474

475 Acknowledgements

476 Funding was provided by the Natural Sciences and Engineering Research Council of

477 Canada Strategic Research Network on Value Chain Optimization (VCO) to E.G. and D.L.M..

478

479

480

481

482

483

484

485

486

487

488

489 References 
Adriaensen, F., Chardon, J.P., De Blust, G., Swinnen, E., Villalba, S., Gulinck, H. \&

491 Matthysen, E. (2003) The application of 'least-cost' modelling as a functional landscape model.

492 Landscape and Urban Planning 64: 233-247.

493

494

Bergerud, A.T. (1974) Decline of Caribou in North-America Following Settlement.

495

Journal of Wildlife Management, 38, 757-770.

496

Bettinger, P., Sessions, J., \& Boston, K. (1997) Using Tabu search to schedule timber

harvests subject to spatial wildlife goals for big game. Ecological Modelling 94(2-3): 111-123.

499

Bevers, M. and Hof, J. (1999) Spatially Optimizing Wildlife Habitat Edge Effects in

501 Forest Management Linear and Mixed-Integer Programs. Forest Science 45(2): 249-258.

Carvajal, R., Constantino, M., Goycoolea, M., Vielma, JP. and Weintraub, A. (2013).

504 Imposing Connectivity Constraints in Forest Planning Models. Operations Research, 61:4, 824-

505836.

506

507

COSEWIC (2000) Canadian species at risk, May 2000. Committee on the Status of

508 Endangered Wildlife in Canada, Environment Canada, Ottawa, Ontario, Canada. 
Cui, W. and Moore, T. 2016. Scheduling Caribou Habitat with LDT. Paper presented at

510 the Ontario Ministry of Natural Resources and Forestry 2016 Annual Forest Analyst Workshop,

511 February 24-24, 2016. Toronto, Ontario.

512

Dantzig, G. (1963). Linear Programming and Extensions. Princeton University Press,

514 New Jersey.

Dantzig, G. B. and Van Slyke, R. M. (1967). Generalized upper bounding techniques.

517 Journal of Computer and System Sciences, 1(3):213-226.

Habitat for Woodland Caribou (Rangifer tarandus caribou), Boreal Population, in Canada: 2011

521 Update. Ottawa, Ontario, Canada. 102 pp. plus appendices.

524 Chilean forest industries. Interfaces, 29(1):7-29. 
Gunn, Eldon. (1991) Some aspects of hierarchical production planning in forest

532 management. Department of Industrial Engineering, Technical University of Nova Scotia.

Gunn, E.A. (2007) Models for Strategic Forest Management. Handbook of Operations

535 Research in Natural Resources (eds A. Weintraub, C. Romero, T. Bjordal \& R. Epstein), pp.

536 317-342. Springer, New York.

539 http://www.gurobi.com.

Gustafson, E.J., Roberts, L.J., \& Leefers, L.A. (2006) Linking linear programming and

542 spatial simulation models to predict landscape effects of forest management alternatives. Journal

543 of Environmental Management 81(4): 339-350.

546 harvest and investment under different objectives. discussion and synthesis. Forest Science,

$547 \quad 18: 1-30$ 
550 programming models I and II for spatial strategic forest management. Canadian Journal of Forest

551 Research-Revue Canadienne De Recherche Forestiere. 47(1): 16-27.

552

553

McGreer, M.T., Mallon, E.E., Vander Vennen, L.M., Wiebe, P.A., Baker, J.A., Brown,

554 G.S., Tal Avgar, T., Hagens, J., Kittle, A.M., Mosser, A., Street, G.M., Reid, D.E.B., Rodgers,

555 A.R., Shuter, J., Thompson, I.D., Turetsky, M.J., Newmaster, S.G., Patterson, B. \&

556 Fryxell, J.M. (2015) Selection for forage and avoidance of risk by woodland caribou

557 (Rangifer tarandus caribou) at coarse and local scales. Ecosphere 6: 288.

O'Brien, D., Manseau, M., Fall, A. \& Fortin, M.J. (2006) Testing the importance of

560 spatial configuration of winter habitat for woodland caribou: An application of graph theory.

561 Biological Conservation 130: 70-83.

562

563 Öhman, K., Edenius, L., \& Mikusinski, G. (2011) Optimizing spatial habitat suitability

564 and timber revenue in long-term forest planning. Canadian Journal of Forest Research 41(3):

$565 \quad 543-551$. 
OMNR (2006). Forest Management Units. Ontario ministry of Natural Resources.

568 https://www.javacoeapp.lrc.gov.on.ca/geonetwork/srv/en/metadata.show?uuid=0104befe-9493-

569 4d9f-b45b-315063374032\&currTab=simple

570

571

OMNR (2007) Strategic forest management model. Software version 3.2. Queen's printer

572 for Ontario, Toronto, ON, Canada.

573

OMNR (2009a). 2009-2019 Forest Management Plan for the Trout Lake Forest. (ed. N.R.

575 Ontario Ministry of Natural Resources (Red Lake District, Domtar Pulp and Paper Products 576 Inc.).

OMNR (2009b) Forest Resources Inventory Technical Specifications 2009. pp. 93.

579 Queen's printer for Ontario, Toronto, ON, Canada. Available at

580 http://www.ontario.ca/document/forest-resources-inventory-technical-specifications.

OMNR (2010) Caribou Range Boundary. Ontario ministry of Natural Resources.

583 Scholars Portal, Ontario Council of University Libraries. http:/geo2.scholarsportal.info/ 
Penner, M., Woods, M., Parton, J. \& Stinson, A. (2008) Validation of empirical yield curves for natural-origin stands in boreal Ontario. Forestry Chronicle 84: 704-717.

591 habitat while maintaining timber yield: A graph theory approach. Canadian Journal of Forest 592 Research-Revue Canadienne De Recherche Forestiere. 46: 914-923.

St. John, R., Öhman, K., Tóth, S., Sandstrom, P., Korosuo, A., \& Eriksson, L. O. (2016). Combining spatiotemporal corridor design for reindeer migration with harvest scheduling in 596 Northern Sweden. Scandinavian Journal of Forest Research. 31(7): 655-663. 
607 for Woodland Caribou Using an Optimization Approach. PLoS ONE 7(2): e31672. doi:

608 10.1371/journal.pone.0031672.

609

610 Thompson, I., Wiebe, P.A., Mallon, E., Rodgers, A.R., Fryxell, J.M., Baker, J.A. \& Reid,

611 D. (2014) Factors influencing the seasonal diet selection by woodland caribou in boreal forests in

612 Ontario. Canadian Journal of Zoology 93(2): 87-98.

614 Harvest Scheduling Models. Environmental Modelling \& Assessment. 13(1):1-15.

617 Woodland caribou extirpation and anthropogenic landscape disturbance in Ontario. Journal of

618 Wildlife Management 71: 1249-1256. 


\section{Tables}

627 Table 1. Classification of stands with respect to their suitability as Caribou habitat. Adapted

628 from Ruppert et al. (2016).

\begin{tabular}{|c|c|c|c|c|}
\hline Rank & Landscape Type & $\begin{array}{l}\text { FRI Forest } \\
\text { Units }\end{array}$ & $\begin{array}{l}\text { Age } \\
\text { (Years) }\end{array}$ & Description \\
\hline 1 & $\begin{array}{l}\text { Mature Jack Pine, } \\
\text { Shallow Soils, and } \\
\text { Rocky Outcrops }\end{array}$ & $\begin{array}{l}\text { PJP, SHA, and } \\
\text { RCK }\end{array}$ & $\geq 60$ & $\begin{array}{l}\text { Mature upland Jack Pine, } \\
\text { shallow soil, and rocky areas }\end{array}$ \\
\hline 2 & Treed Muskeg & TMS & - & Treed muskeg \\
\hline 3 & $\begin{array}{l}\text { Mature Conifer } \\
\text { Mixedwood }\end{array}$ & $\begin{array}{l}\text { PJM, CMX, PRW, } \\
\text { SBM, and SBP }\end{array}$ & $>71$ & $\begin{array}{l}\text { Mature upland conifer } \\
\text { mixedwood and Black Spruce }\end{array}$ \\
\hline 4 & $\begin{array}{l}\text { Mature Lowland } \\
\text { Conifer }\end{array}$ & $\mathrm{OCL}$ and $\mathrm{SBL}$ & $\geq 60$ & $\begin{array}{l}\text { Mature lowland conifer } \\
\text { mixedwood and Black Spruce }\end{array}$ \\
\hline 5 & $\begin{array}{l}\text { Intermediate Upland } \\
\text { Mixedwood }\end{array}$ & $\begin{array}{l}\text { CMX, HMX, PJM, } \\
\text { and SBM }\end{array}$ & $\geq 46$ & $\begin{array}{l}\text { Mixedwood stands of } \\
\text { intermediate age }\end{array}$ \\
\hline 6 & $\begin{array}{l}\text { Young Conifers and } \\
\text { Hardwoods }\end{array}$ & $\begin{array}{l}\text { POA and BWD } \\
\text { (along with all } \\
\text { other conifer } \\
\text { stands) }\end{array}$ & - & $\begin{array}{l}\text { All dominant hardwood stands } \\
\text { and younger conifer stands }\end{array}$ \\
\hline 7 & Water and Wetlands & WAT and OMS & - & Lakes, Rivers, and marsh areas \\
\hline 8 & Recent Disturbance & $\begin{array}{l}\text { All merchantable } \\
\text { wood units }\end{array}$ & $<20$ & $\begin{array}{l}\text { Recently disturbed areas (e.g., } \\
\text { harvest, fire) }\end{array}$ \\
\hline 9 & Linear Features & - & - & $\begin{array}{l}\text { Current road and utility line } \\
\text { infrastructure }\end{array}$ \\
\hline
\end{tabular}

629 


\section{$630 \quad$ Figure Labels}

631 Figure 1. The Trout Lake Forest Management Unit (FMU) with woodland caribou distribution

632 (light grey) and all FMUs (dark grey outline). Woodland caribou range data is from OMNR

633 (2010) and FMU data from OMNR (2006). Adapted from Ruppert et al. (2016).

635 Figure 2. Schematic diagram of the replanning framework.

637 Figure 3. ECA levels for all of the planning models over an 11 period planning horizon. This 638 includes the harvesting heuristic, the caribou mosaic, the replanning framework, and the no 639 harvest models.

641 Figure 4. Allocated harvest over the entire planning horizon (11 planning periods; 107 years) for 642 the Trout Lake forest for $(\mathrm{A}, \mathrm{B})$ the entire spatial extent and $(\mathrm{C}, \mathrm{D})$ a section from the 643 southwestern corner. Shown are solutions using $(A, C)$ the replanning framework and (B,D) the 644 harvesting heuristic. Dark areas indicate planned harvests.

646 Figure 5. The assigned caribou habitat value on the terminal landscape under the (A,C,E)

647 replanning framework and $(\mathrm{B}, \mathrm{D}, \mathrm{F})$ harvesting heuristic. Shown is the $(\mathrm{A}, \mathrm{B})$ entire spatial extent 648 of the Trout Lake forest, (C,D) a section from the northeast corner, and (E,F) a section from the 649 western edge. Lighter colours on the map indicate higher quality caribou habitat given by the 650 ECA metric. 
652 Figure 6. The overall (A) ECA for each of the harvest scenario during the first 5 planning

653 periods and the (B) ECA for each of the harvest scenarios during the last 6 periods

654

655

656

657

658

659

660

661

662

663

664

665

666

667

668

669

670

671

672

673

674 


\section{Figures}

676

$677 \quad$ Figure 1.

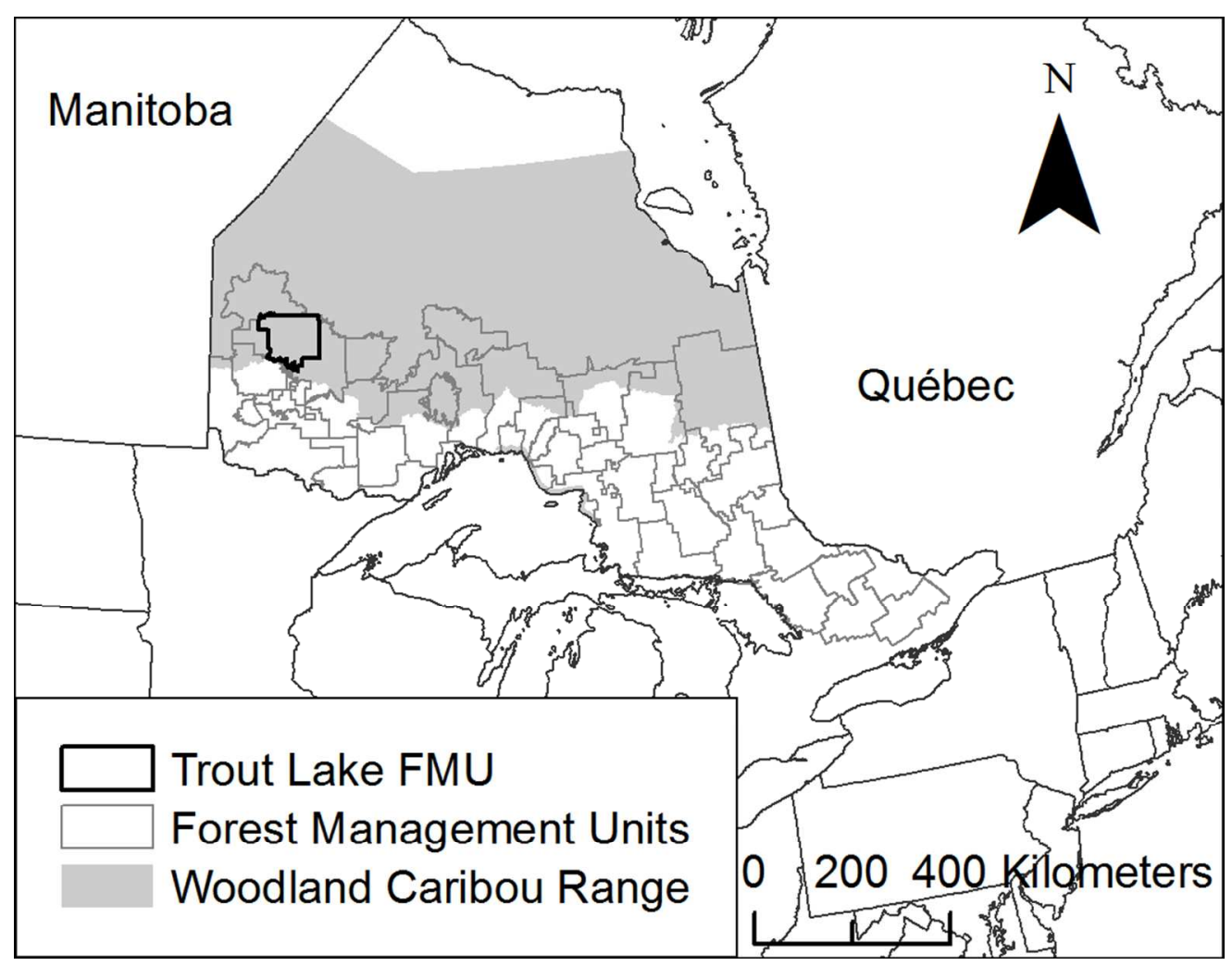

678 
679 Figure 2.

1: Compute ECA based on the current state of the forest

2: Generate and solve the LP model

3: Update the state of the forest at the start of the next period assuming the LP solution harvests have been implemented.

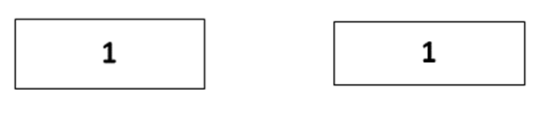

1
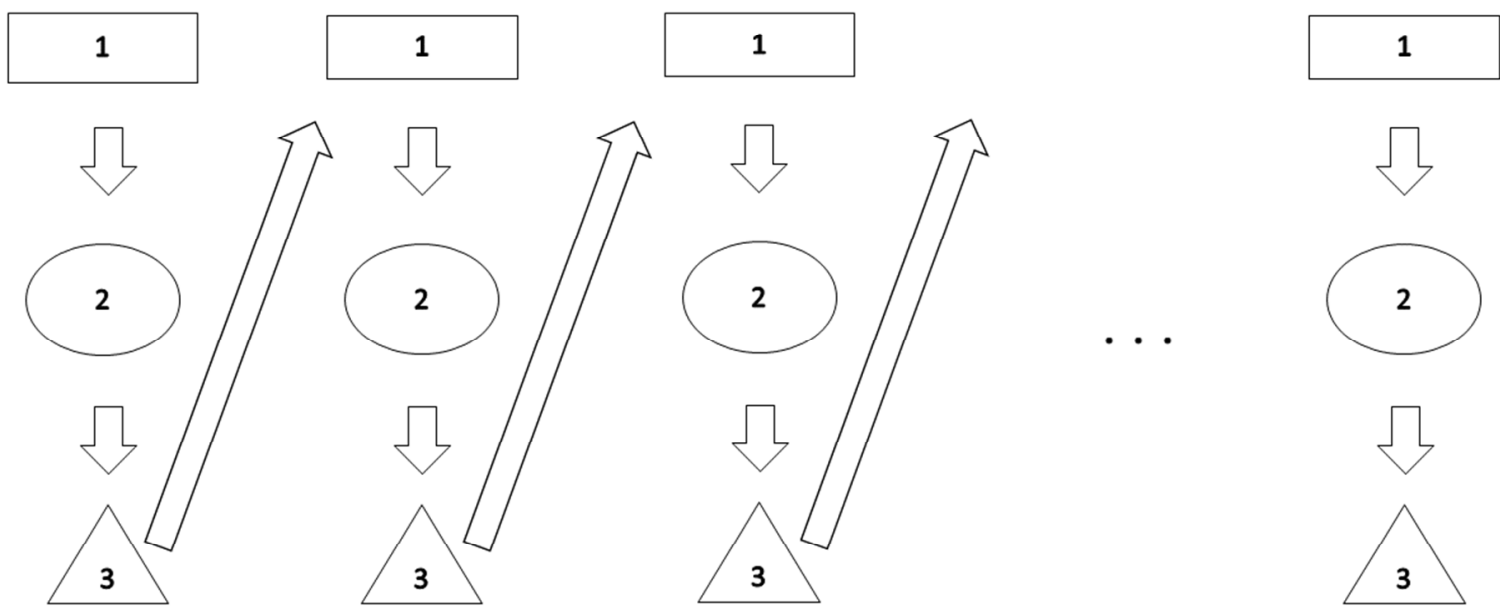

Period 1

Period 2

Period 3

Period 11

680 
Figure 3.

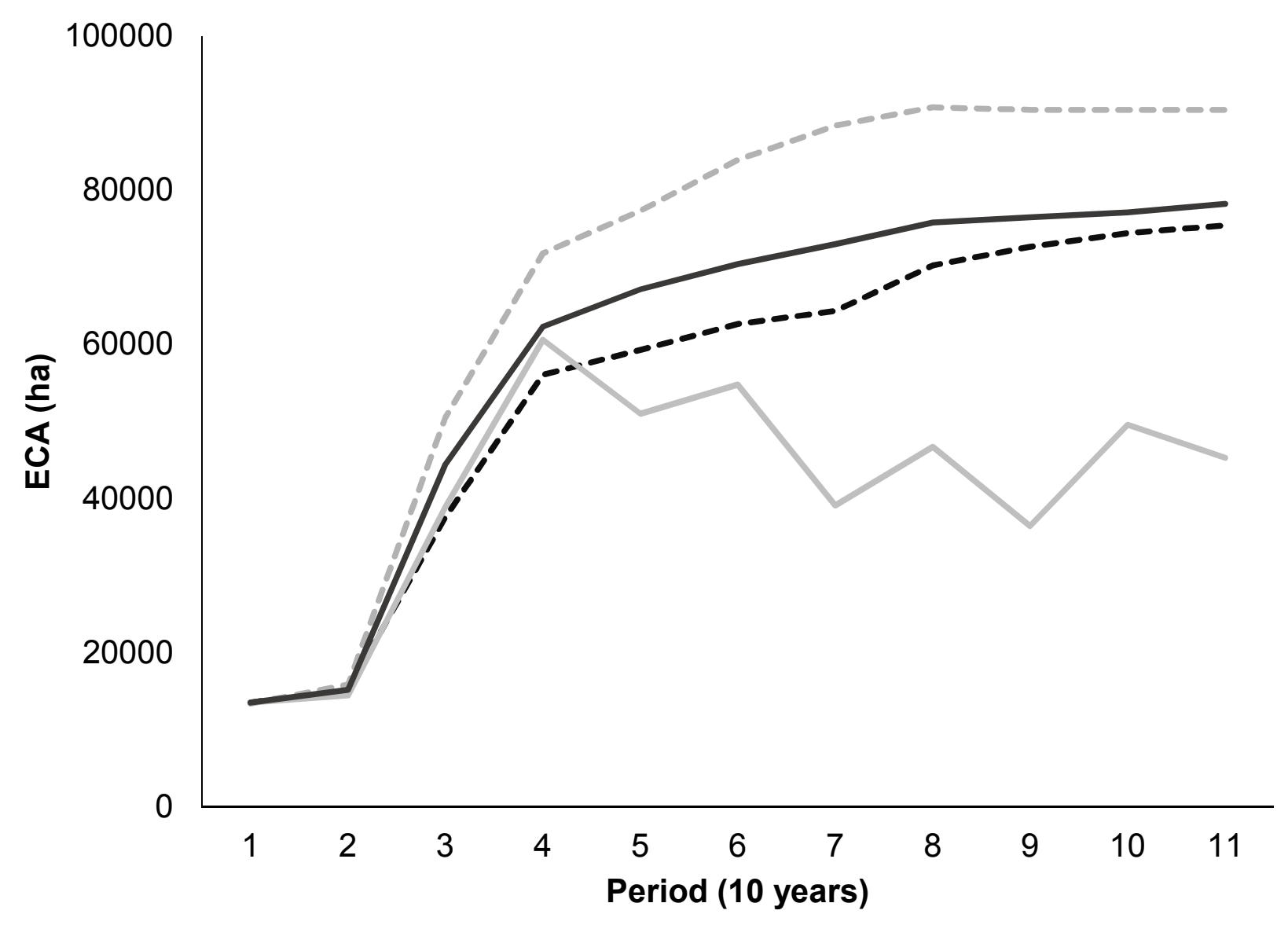

- - Heuristic - - No harvest Mosaic - Replanning 


\section{$681 \quad$ Figure 4.}

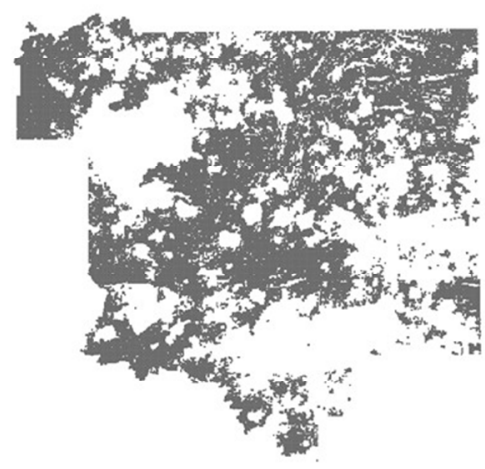

A

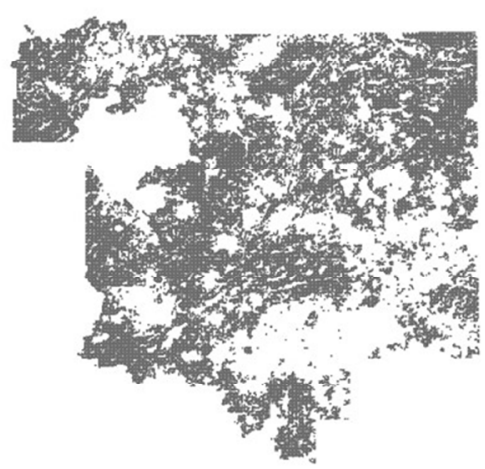

B
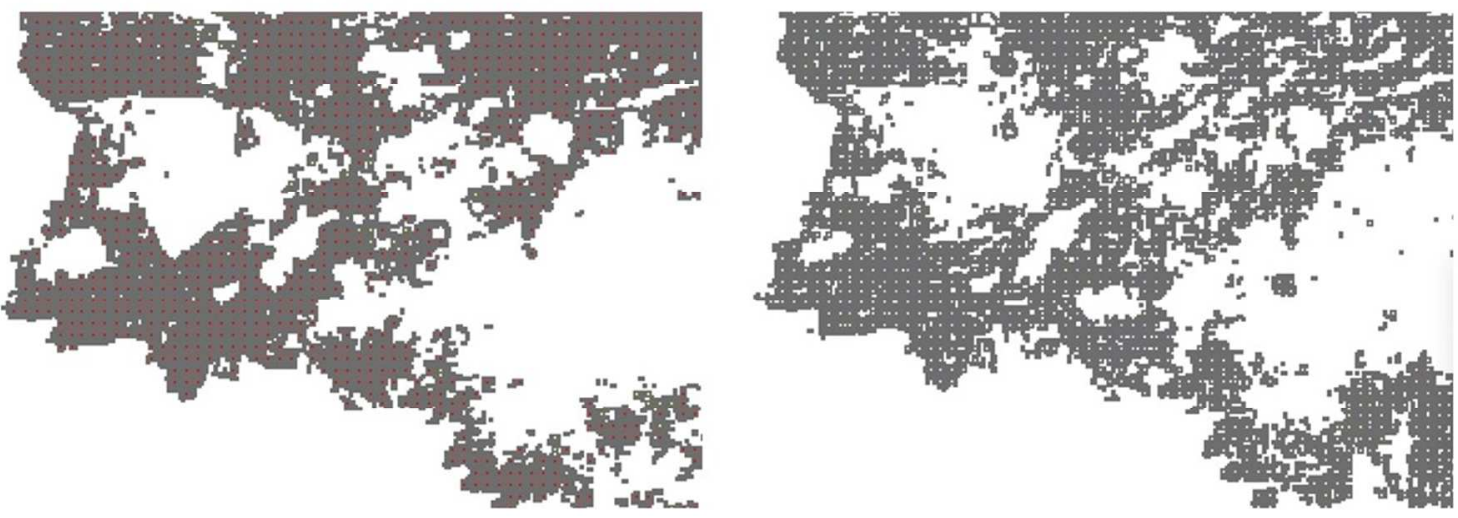

C

D 


\section{$683 \quad$ Figure 5.}

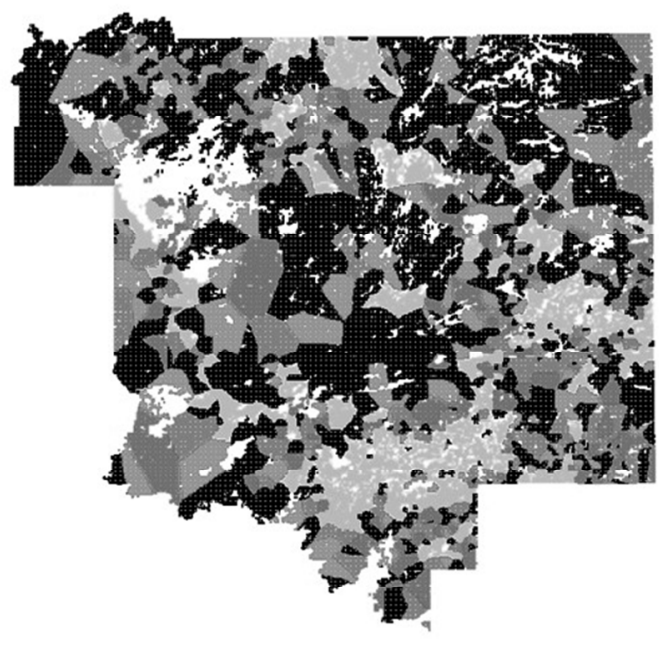

A

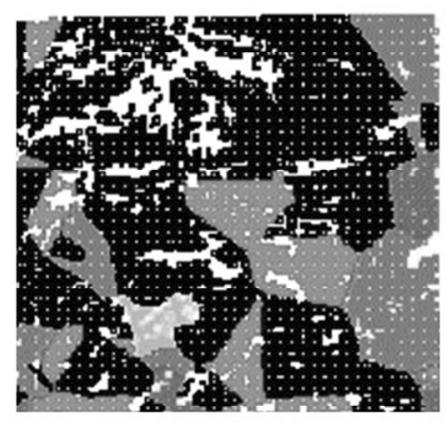

C

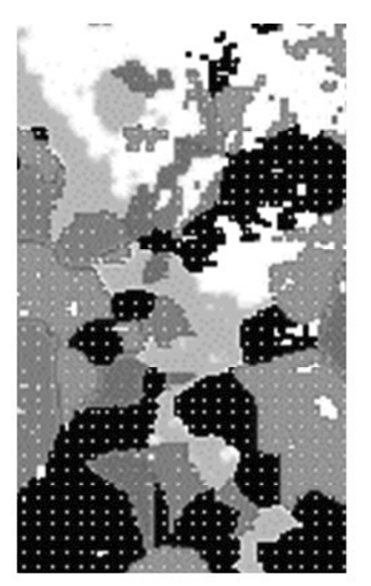

E

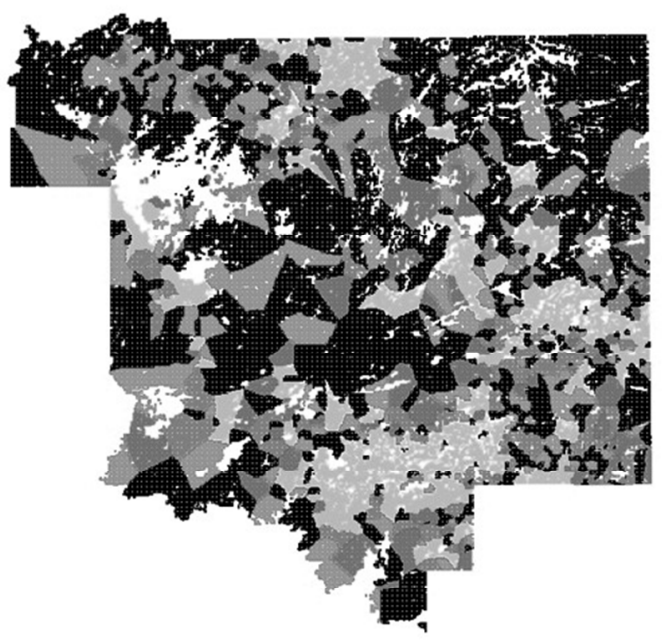

B

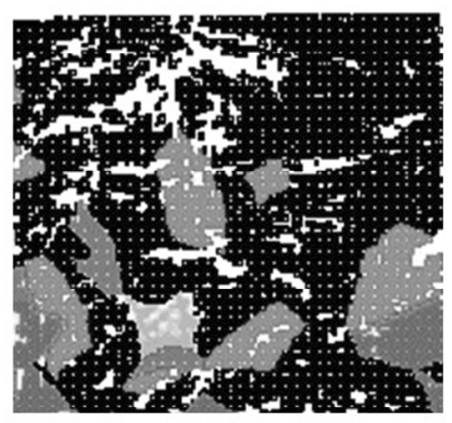

D

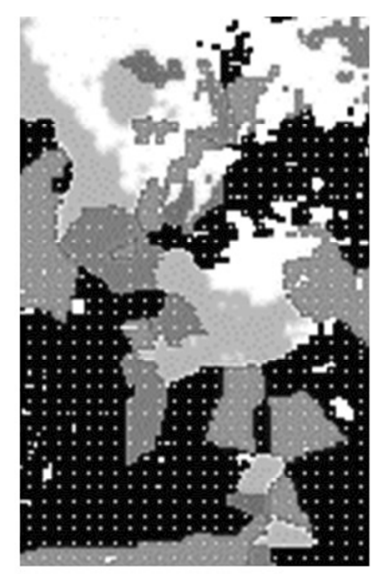

F 
Figure 6.
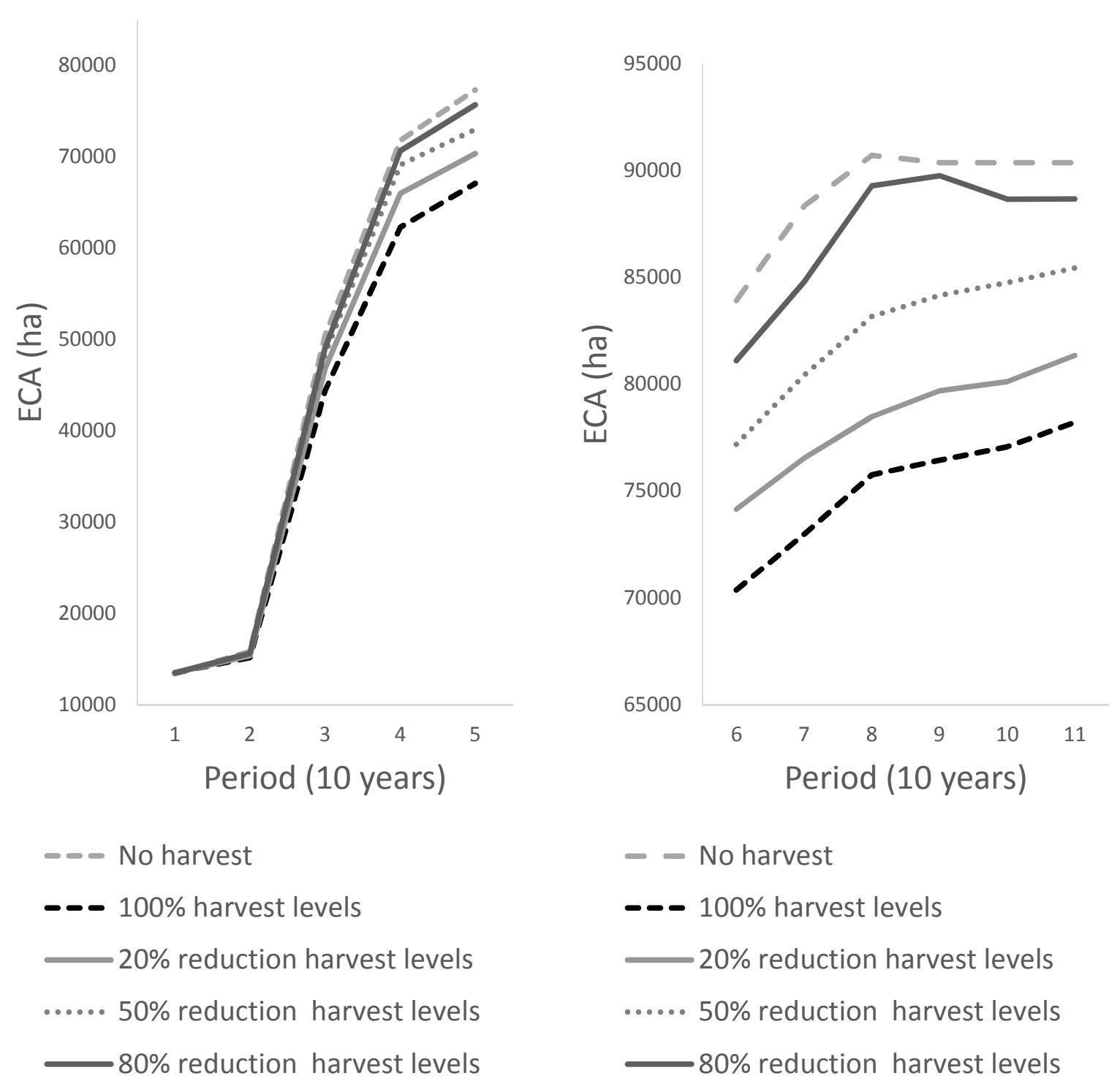

684

- No harvest

- - 100\% harvest levels

$20 \%$ reduction harvest levels

..... 50\% reduction harvest levels $-80 \%$ reduction harvest levels

A

B 


Rank $\quad$ Landscape Type
1 Mature Jack Pine, Shallow Soils, and Rocky Outcrops
2 Treed Muskeg
3 Mature Conifer Mixedwood
4 Mature Lowland Conifer
5 Intermediate Upland Mixedwood
6 Young Conifers and Hardwoods
7 Water and Wetlands
8 Recent Disturbances
9 Linear Features

FRI Forest Units

PJP, SHA, RCK

TMS

PJM, CMX, PRW, SBM, SBP

$\mathrm{OCL}, \mathrm{SBL}$

CMX, HMX, PJM, SBM

POA, BWD, all other conifer stands

WAT, OMS

All merchantable wood units 


$\begin{array}{ll}\text { Age (Years) } & \text { Description } \\ >=60 & \text { Mature upland Jack Pine, shallow soil and rocky areas } \\ -- & \text { Treed muskeg } \\ >71 & \text { Mature upland conifer mixedwood and Black Spruce } \\ >=60 & \text { Mature lowland conifer mixedwood and Black Spruce } \\ >=46 & \text { Mixedwood stands of intermediate age } \\ -- & \text { All dominant hardwood stands and younger conifer stands } \\ -- & \text { Lakes, Rivers, and marsh areas } \\ <20 & \text { Recently disturbed ares (e.g. harvest, fire) } \\ -- & \text { Current road and utility line infrastructure }\end{array}$

